I Universidade Federal de São Carlos (UFSCar),

Departamento de Ciências Sociais, São Carlos, SP, Brasil

felipevelden@yahoo.com.br

https://orcid.org/o0oo-0002-5684-I 250

Felipe Vander Velden'

\title{
OS AINU E SUAS PLANTAS NO NORTE DO JAPÃO
}

Williams, Dai. (20I7). Ainu Ethnobiology. Tacoma, WA:

Society of Ethnobiology (Contributions in Ethnobiology Series).

O diálogo entre antropólogos e etnobiólogos nunca foi fácil, sobretudo por conta da insatisfação dos primeiros com o prefixo etno-, que, se define o próprio campo de investigação dos segundos, exprime, para a antropologia, o vício fatal da etnobiologia: aquele que toma a biologia científica moderna como a detentora do acesso ao mundo, ao passo que todas as demais (etno)biologias (ou biologias folk ou de folk) ou (etno)ciências podem produzir tão somente versões ou visões sobre este mesmo (único) mundo. Os avanços recentes da virada ontológica seguramente vieram para sepultar o interesse antropológico pelo que faz a etnobiologia, ao radicalmente recusar a afirmação de um mundo material (e, assim, natural ou biótico) comum e, mais ainda, a pretensão de que apenas uma forma de conhecimento é capaz de o descortinar.

Tais precauções, contudo, não devem nos impedir de apreciar o escopo por vezes bastante amplo dos trabalhos etnobiológicos e o fato de que seus trabalhos usualmente fornecem grande quantidade e riqueza de informações sobre os conhecimentos indígenas, tradicionais ou populares dos entes que povoam os mundos desses mesmos povos. Esse é, certamente, o caso do livro Ainu ethnobiology, do antropólogo, geógrafo e arquiteto Dai Williams, parte de uma série de monografias (Contributions to Ethnobiology) editada pela Society of Ethnobiology e destinada a oferecer ao público leitor trabalhos de fôlego no campo da etnobiologia, sendo - pode-se ler na quarta capa do volume - "the only mo- 
nograph series devoted expressly to representing the breadth of ethnobiological topics". ${ }^{\text {I }}$

Os Ainu, ou Aynu, constituem um dos grupos humanos mais singulares. Prováveis descendentes dos habitantes nativos do Japão - e de arquipélagos circunvizinhos, Sakhalina e as Kurilas, ambas no leste da Federação Russa, de onde virtualmente desapareceram no século XIX (Ohnuki-Tierney, I974) -, os Ainu foram paulatina e violentamente empurrados para o norte com a colonização japonesa do arquipélago, terminando por radicar-se apenas na mais setentrional das ilhas, Hokkaido (Walker, 2006). Sua língua ou línguas - não tem qualquer parentesco com o japonês nem, ao que parece, com nenhum outro idioma falado no planeta (Shibatani, I 990). Além disso, os Ainu conservaram-se caçadores e coletores durante muito tempo após a ocupação japonesa da região, expressando conexões principalmente com populações do extremo oriente siberiano.

O livro Ainu ethnobiology, contudo, apresenta uma coleção de memórias: rico testemunho dos saberes e usos cotidianos da flora e da fauna pelos Ainu, que tiveram de ser buscados em trabalhos e observações realizados entre o século XVIII e o início do século XX. Ainda assim, relata-nos o autor, boa parte das informações sobre a ecologia de Hokkaido procede do profundo conhecimento que esse povo ainda tem de seu território e dos seres com os quais o partilham, e que vem sendo pesquisado por Williams desde I997.
É preciso reconhecer que, embora prometa tratar da etnobiologia ainu, a obra concentra-se basicamente no conhecimento botânico desse povo, que ocupa os quatro principais capítulos; há pouquíssima informação zoológica, distribuída ao longo dos capítulos iniciais e em dois curtos apêndices (Fauna of Hokkaido e Birds of Hokkaido). Além disso, os primeiros quatro capítulos, destinados - supõe-se - a oferecer um panorama histórico e etnográfico dos Ainu, de modo a introduzir seu detalhado saber sobre as criaturas não humanas (majoritariamente, como vimos, plantas) com quem convivem, deixam muito a desejar. O panorama histórico é muito breve, e é sintomático - tratando-se do trabalho de um etnobiólogo - que o terceiro capítulo, intitulado Ainu Society, apresente basicamente uma descrição dos seus ciclos econômicos sazonais, como se sua sociedade pudesse ser reduzida à produção.

Há outros problemas menores: na página 55, por exemplo, o autor faz referência aos cogumelos (fungi), que são, desse modo, incluídos, sem mais explicações, entre os vegetais conhecidos e coletados pelos Ainu. Nenhuma reflexão, aliás, sobre o modo como os Ainu conceitualizam e categorizam os seres não humanos nos é fornecida: nada sabemos das lógicas nativas de apreensão das plantas e da percepção de suas semelhanças e diferenças - nem, portanto, de qualquer esboço de classificação. Ficamos, assim, reféns de uma listagem de vegetais e seus empregos, com a categoria científica (botânica) "vegetal" (ou "planta") intacta, 
em nada submetida a uma certamente existente crítica Ainu, ainda que ela não possa mais ser recuperada em sua antiga integridade. Assim, o trabalho de Dai Williams acaba muito aquém dos reconhecidos esforços de certos etnobiólogos (cf. Hunn, I978; Posey, 2003, para ficar em exemplos americanos consagrados) por descortinar os esquemas classificatórios indígenas, para além da catalogação sistemática de seres e os saberes e utilidades a eles associados.

A razão utilitária, desse modo, informa o interesse do autor nas plantas do universo desse povo nativo dos duros ambientes naturais do Extremo Oriente. Nenhum problema com isso, obviamente, exceto pelo fato de que uma impressionate diversidade - quase 500 plantas conhecidas e nomeadas pelos Ainu em Hokkaido, na Sakhalina e nas Kurilas - é reduzida, aqui, às cerca de 160 que são coletadas porque são úteis. Não obstante, os cinco capítulos finais - que são divididos pela estação de coleta das plantas, suas flores, frutos, brotos, raízes, galhos, madeiras, resinas - são substantiva prova documental do enorme conhecimento ainu das regiões por eles ocupadas. Nesses captíulos o autor colige copiosa documentação sobre a relação dos Ainu com vegetais, o que inclui não apenas informações sobre suas utilidades, mas também sobre a presença mítica, histórica e ritual de várias espécies. Diga-se de passagem que há uma expressiva quantidade de plantas comestíveis aproveitadas nessas regiões de condições climátias severas, explicitando, uma vez mais, o inesgotável engenho humano na busca não apenas da subsistência, mas também - e isso aparece com certo destaque no livro - do gosto culinário e dos prazeres gastronômicos.

Desse modo, preservado o básico da tradição etnobiológica - o inventário de formas naturais conhecidas e empregadas por um povo -, espera-se que volumes como esse, interessantíssimo em vários sentidos, estimulem nos antropólogos o desejo pelo mesmo espírito globalizante que parece animar nossos colegas envolvidos com as biologias de folk: uma atenção detalhada, quase obsessiva, ao mundo natural, se possível na mesma intensidade que demonstram as comunidades em estudo. Que outra foi uma das máximas lições de Lévi-Strauss? Não à toa, os exemplos da notável riqueza e complexidade dos saberes nativos trazidos em O pensamento selvagem (Lévi-Strauss, I 997) são, em grande parte, oriundos dos esforços de etnobiólogos.

Pode-se dizer que virtualmente não existe nada sobre os Ainu escrito ou publicado no Brasil, e mesmo aqueles proficientes em línguas europeias majoritárias não dispõem de muito material: a maioria dos trabalhos foi e tem sido mesmo, obviamente, publicada em japonês (com alguma coisa editada em russo). Ainu ethnobiology, assim, abre mais uma janela acessível ao conhecimento dessa que constitui uma das mais fascinantes e enigmáticas sociedades deste planeta.

Recebida em 26/5/20I8 | Aprovada em I6/I I/20I8 


\section{NOTA}

I Os títulos da coleção podem ser conferidos no website <https://ethnobiology.org/publications/contributions.>

\section{REFERÊNCIAS BIBLIOGRÁFICAS}

Hunn, Eugene. (1978). Tzeltal folk zoology: the classification of discontinuities in nature. Cambridge: Academic Press. Lévi-Strauss, Claude. (I997) [I962]. O pensamento selvagem. Campinas: Papirus.

Ohnuki-Tierney, Emiko. (1974). The Ainu of the northwest coast of southern Sakhalin. New York: Holt, Rinehart and Winston.

Posey, Darrell. (2003). Kayapó ethnoecology and culture. London: Routledge. Shibatani, Masayoshi. (I990). The languages of Japan. Cambridge: Cambridge University Press.

Walker, Brett. (2006). The conquest of Ainu lands: ecology and culture in the Japanese expansion, I590-I800. Berkeley: University of California Press.

Felipe Vander Velden é mestre e doutor em antropologia social pela Universidade Estadual de Campinas (Unicamp), e pós-doutor pela Aarhus University, na Dinamarca. É professor do Departamento de Ciências Sociais e do Programa de Pós-Graduação em Antropologia Social da UFSCar desde 20 I. Trabalha com os índios Karitiana desde 2002, focalizando, principalmente, as relações entre humanos e animais. Publicou Inquietas companhias: sobre os animais de criação entre os Karitiana (20I2) e Joias da floresta: antropologia e tráfico de animais (2018). 